\title{
Minireview
}

nephron

Clinical Practice

\section{Non-Calcium-Containing Phosphate Binders: Comparing Efficacy, Safety, and Other Clinical Effects}

\author{
João M. Frazão ${ }^{a}$ Teresa Adragão ${ }^{b}$ \\ a Nephrology Department, Hospital de S. João, School of Medicine, University of Porto and Nephrology Research \\ and Development Unit, University of Porto, Porto, and ${ }^{\mathrm{b}}$ Nephrology Department, Santa Cruz Hospital, \\ Lisbon, Portugal
}

\section{Key Words}

Chronic kidney disease - Mineral and bone disorder •

Phosphate binders $\cdot$ Hyperphosphataemia

\begin{abstract}
Phosphate-binder therapy for hyperphosphataemia is key to the treatment of patients with chronic kidney disease (CKD)mineral and bone disorder (MBD). Calcium-free phosphate binders are increasingly favoured since calcium-based agents potentially cause harmful calcium overload and vascular calcification that confound the benefits of reducing serum phosphorus. Several calcium-free phosphate binders are available, including the non-absorbed agent sevelamer and the absorbed agents, e.g. lanthanum and magnesium salts. Randomised controlled studies consistently show that sevelamer and lanthanum carbonate offer equivalent lowering of serum phosphorus and often effectively achieve phosphorus targets versus calcium salts, with sevelamer having a positive effect on bone disease, vascular calcification, and patient-level outcomes in dialysis patients in several trials. There is also evidence that lanthanum carbonate can improve bone health, but data are limited to its effects to vascular calcification or patient-level outcomes. Magnesium salts have also been shown to reduce serum phosphorus levels, but clear evidence is lacking on bone, vascular, or clinical outcomes. It also remains to be established whether long-
\end{abstract}

term systemic accumulation of lanthanum and magnesium, in tissues including bone, has clinically relevant toxic effects. This review summarises the evidence of efficacy and safety for newer calcium-free phosphate binders in CKD-MBD management.

Copyright $\odot 2012$ S. Karger AG, Basel

\section{Introduction}

Hyperphosphataemia is a major clinical manifestation of declining kidney function. Although a phosphate-positive balance occurs from early stages of chronic kidney disease (CKD), hyperphosphataemia is usually delayed until the later stages by elevation of parathyroid hormone (PTH) and fibroblast growth factor (FGF)-23 which augment phosphaturia [1]. The effects of high phosphorus levels on PTH, and more recently on FGF-23, are now recognised to play a key part in the pathogenesis of CKDmineral and bone disorder (MBD) [2, 3]. It is, however, increasingly realised that high serum phosphorus is also actively involved in soft tissue and vascular calcification [4]. This may contribute to the association consistently reported in epidemiologic studies between high serum phosphorus levels and cardiovascular disease (CVD) and mortality in patients with CKD stages $3-5$ and 5D $[5,6]$. Moreover, although no direct interventional evidence is

\section{KARGER \\ Fax +4161306 1234 \\ E-Mail karger@karger.ch}

www.karger.com (c) 2012 S. Karger AG, Basel

$1660-2110 / 12 / 1202-0108 \$ 38.00 / 0$

Accessible online at:

www.karger.com/nec
João M. Frazão

Hospital de S. João, Serviço de Nefrologia

Alameda Hernâni Monteiro

PT-4200 Porto (Portugal)

Tel. +351919568 100, E-Mail jmmdfrazao@gmail.com 
available to show lowering phosphorus can improve such outcomes, reducing serum phosphorus levels was associated with improved outcomes, even in normophosphataemic patients, in a recent prospective observational cohort study [7].

Serum phosphorus is, therefore, widely accepted as a biochemical endpoint with probable clinical benefit, and its control as part of managing phosphate retention/hyperphosphataemia can possibly improve not only bone disease but also potentially reduce CVD morbidity and mortality in CKD patients. Thus, clinical guidelines emphasise the importance of early and effective phosphate control, with the $2009 \mathrm{KDIGO}$ guidelines suggesting this should involve maintaining serum phosphorus in the normal range in CKD stages 3-5 and lowering elevated phosphorus levels towards the normal range in CKD stage $5 \mathrm{D}$ [8]. The KDIGO guidelines also consider that CKD patients with known vascular and valvular calcifications should be considered to be at highest cardiovascular risk and suggest evaluating vascular or valvular calcifications in these patients. It is reasonable to use this information to guide the management of CKD-MBD [8], although a recent article by Martin and Gonzalez [9] discusses the fact that increases in PTH and FGF-23 occur as early as CKD stages 3-4 to compensate for phosphate retention, and are observed before hyperphosphataemia develops; therefore, earlier treatment may be warranted to help maintain near-normal phosphorus for longer as CKD progresses. This early treatment has been discussed as a means of potentially reducing the risk of development of renal secondary hyperparathyroidism and all of the adverse clinical consequences of poorly controlled CKD-MBD [10]. Other guideline bodies such as the NKF KDOQI in the USA [11] have recommended serum phosphorus targets of 2.7-4.6 $(0.87-1.49 \mathrm{mmol} / \mathrm{l})$ in CKD stages $3-5$, and $3.5-5.5 \mathrm{mg} / \mathrm{dl}(1.13-1.78 \mathrm{mmol} / \mathrm{l})$ in CKD stage $5 \mathrm{D}$.

Phosphorus reduction and control is currently achieved using several approaches. First, dietary restriction of total phosphate intake [12], including phosphatecontaining additives [13], is often part of CKD management, especially before onset of dialysis, but its usefulness can require lowering protein intake below $1.0-1.2 \mathrm{~g} / \mathrm{kg} /$ day which risks protein malnutrition [14]. Second, dialysis phosphate removal can be used, but the usual dialysis prescription may be insufficient to substantially reduce phosphorus levels which can be affected by post-dialytic rebound [15]. Finally, oral phosphate binders can be prescribed; these represent an effective and simple means to bind and eliminate dietary phosphate in the intestines.
A range of phosphate binders currently available for long-term use includes calcium-based phosphate binders (calcium carbonate and acetate) and calcium-free binders (aluminium hydroxide, lanthanum carbonate, magnesium carbonate, sevelamer hydrochloride, and sevelamer carbonate). Current phosphate binders are all effective in lowering phosphorus, so the main considerations for selection should be its other characteristics, including absorbability (ideally non-absorbed), adequate gastrointestinal tolerability, and cost or cost-effectiveness. The latter can be hard to quantify accurately and is outside the scope of this review.

These characteristics are influenced by the chemical properties of the phosphate binders. Aluminium is known to accumulate with highly toxic effects, including dialysis encephalopathy, osteomalacia, and anaemia; thus, the use of aluminium hydroxide is currently restricted to short-term salvage therapy, although the true toxicity of aluminium as a binder has recently been questioned by Mudge et al. [16], who suggest that, with improved treatment and testing of dialysis water in most haemodialysis units and regular measurement of serum aluminium in dialysis patients taking aluminium binders, further studies comparing all binders, including aluminium, are warranted [16].

Calcium acetate and calcium carbonate are often considered current standard therapy, since they very effectively lower serum phosphorus levels $[17,18]$, and are consequently often used as a benchmark in comparative clinical studies. However, more recently, studies have evaluated the relative effects of phosphate binders on bone, vascular and clinical outcomes. This is important since it is now recognised that calcium-based phosphate binders can lead to calcium intake in excess of the recommended dietary intake, which can increase the risk of calcium overload and hypercalcaemia linked to low-turnover bone disease and vascular calcification [19].

This review focuses on the use of the newer aluminium-free, calcium-free phosphate binders to maintain serum phosphorus within 'normal' targets as suggested by KDIGO and KDOQI guidelines while minimising safety issues during long-term CKD management.

\section{Comparative Efficacy of Current Phosphate Binders}

\section{Sevelamer Hydrochloride and Carbonate}

Sevelamer is a polymeric amine, which is the only nonabsorbed, non-calcium-based phosphate binder currently indicated for phosphate control [20,21]. It does not 
Fig. 1. Serum phosphorus control in sevelamer- or calcium-treated haemodialysis patients over 12 months in the TTG study (from Braun et al. [24], with permission).

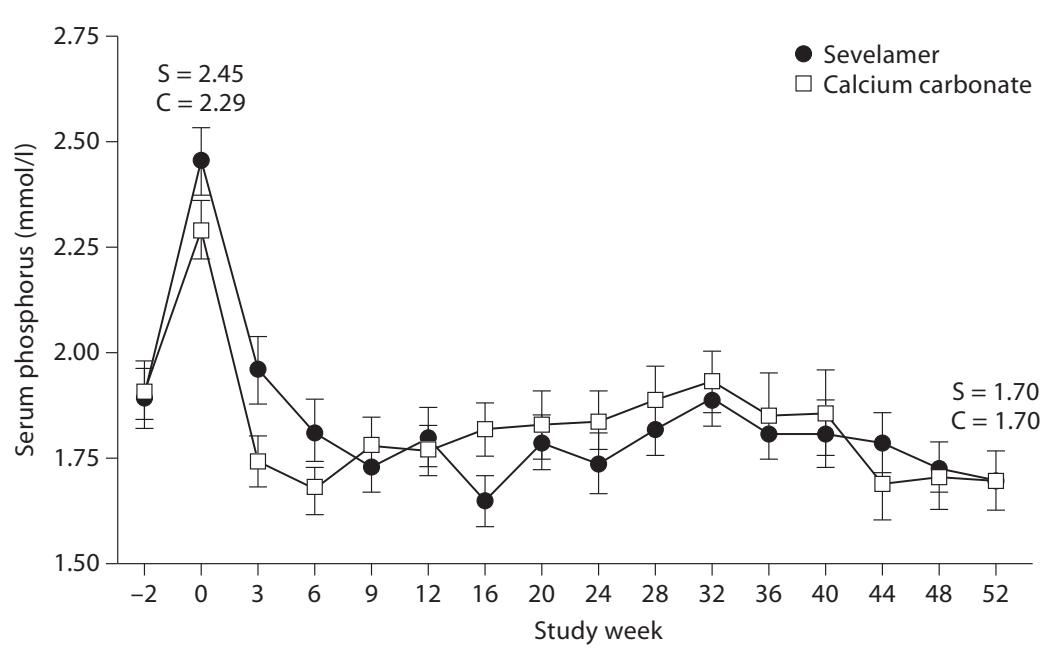

ber states and several other countries, sevelamer carbonate is indicated to lower phosphorus levels in hyperphosphataemic CKD stage $3-5$ patients not on dialysis $[33,34]$.

Importantly, dose titration of sevelamer to 'treat to target' can help patients achieve a high rate of phosphate control within the recommended (KDOQI) target range. This has been shown in several recent studies in patients with CKD stages 3-5 and CKD stage 5D. For example, Delmez et al. [35] showed 70\% of haemodialysis patients on sevelamer hydrochloride versus $71 \%$ on sevelamer carbonate averaged phosphorus levels within $3.5-5.5 \mathrm{mg} / \mathrm{dl}$ over 8 weeks of treatment. Fishbane et al. [31] similarly reported that $64 \%$ of haemodialysis patients taking sevelamer hydrochloride, and 54\% taking sevelamer carbonate powder once daily, were able to maintain phosphorus levels of $3.5-5.5 \mathrm{mg} / \mathrm{dl}$ after 24 weeks. Finally, Ketteler et al. [33] observed 75\% of CKD stage 4 and 70\% of CKD stage 5 patients before onset of dialysis had phosphorus within $2.7-4.6 \mathrm{mg} / \mathrm{dl}$ after 8 weeks.

\section{Lanthanum Carbonate}

Lanthanum carbonate is a non-calcium-based phosphate binder that has shown efficacy at reducing phosphorus in short-term clinical trials [36]. In one study, Hutchison et al. [37] showed a small improvement in the percentage of dialysis patients with serum phosphorus $<5.6 \mathrm{mg} / \mathrm{dl}$ from $35 \%$ at baseline to $48 \% 12$ weeks after switching to lanthanum, but only $23 \%$ of the patients treated with the maximum dose of lanthanum, $4,500 \mathrm{mg} /$ day, were controlled to KDOQI targets. Mehrotra et al. 
Fig. 2. Serum phosphorus levels associated with use of lanthanum and calcium-based phosphate binders over 12 months (from Hutchison et al. [40], with permission).

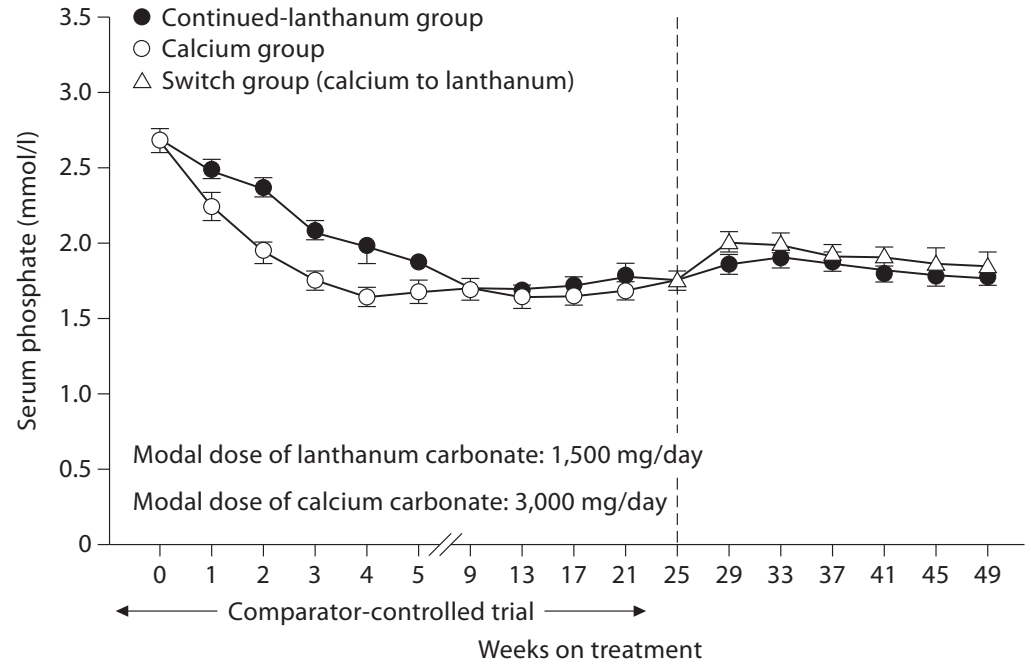

Weeks on treatment
[38] found that $54 \%$ of patients on standard strength lanthanum $(3,000 \mathrm{mg} /$ day $)$ were within phosphorus targets at week 4; whereas a further $25 \%$ (on 3,000 mg/day), $38 \%$ (on $3,750 \mathrm{mg} /$ day) and $32 \%$ (on $4,750 \mathrm{mg} /$ day) of those outside phosphorus targets (46\%) were subsequently within phosphorus targets at week 8. Sprague et al. [39] reported $44.6 \%$ of CKD stage 3-4 patients achieved phosphorus $<4.6 \mathrm{mg} /$ day after 8 weeks versus $26.5 \%$ in the matching placebo group (not statistically different). In addition, the long-term use of lanthanum carbonate (up to 3 years) was shown to maintain stable phosphorus levels similar to those with calcium salts or preexisting phosphate binders (fig. 2) [40].

While most data on lanthanum carbonate and sevelamer show that both have comparable efficacy to calcium-based binders, only one published clinical study directly compares their efficacy [41]. In the primary analysis, there was no significant difference in serum phosphorus levels after treatment with fixed doses of lanthanum (2,250-3,000 mg/day) versus sevelamer (4,800$6,400 \mathrm{mg} /$ day). In fact, both treatments may reduce phosphate levels depending on an adequate prescribed dose and on patient adherence due to, for example, fewer tablets to obtain similar results with lanthanum carbonate, or the powder formulation of sevelamer carbonate. Therefore, it remains to be seen whether any clinically meaningful differences in efficacy exist between the two phosphate binders.

Findings from a meta-analysis showed that, compared with calcium-based agents, lanthanum significantly de- creased end-of-treatment serum calcium and calciumphosphorus product levels, but with similar end-of-treatment phosphorus levels [27].

\section{Magnesium Salts}

Magnesium salts are known to be potentially effective phosphate binders, although, to date, only small- to medium-sized interventional trials have demonstrated this [42]. Several early studies evaluated magnesium hydroxide with limited success (due to tolerability) [43, 44], others studied combinations of magnesium carbonate and calcium carbonate together with reductions in dialysate magnesium, which reduced serum phosphorus while limiting increases in magnesium $[45,46]$. However, magnesium-based phosphate binders have not been widely adopted since calcium therapy was perceived to be more than adequate and effective.

Recently, magnesium has received renewed interest as an alternative to calcium, stimulated by its potential beneficial effects versus calcium's potential harmful effects on bone health and vascular processes in CKD-MBD (see below). Several magnesium-containing regimens have been investigated in a limited number of small clinical studies. In one pilot study, magnesium carbonate showed good phosphate-lowering efficacy (fig. 3) [47]. Other studies have reported effective phosphate control with combinations of magnesium carbonate and calcium carbonate or calcium acetate $[48,49]$. This has led to some use of a formulation of magnesium carbonate and calcium acetate, which was recently authorised for use as a 


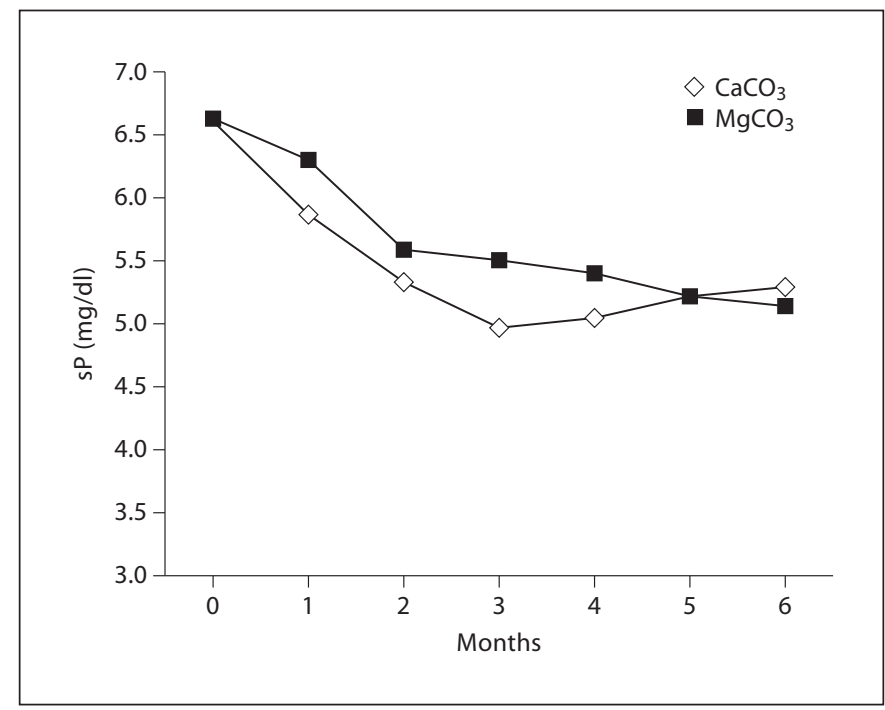

Fig. 3. Serum phosphorus levels with magnesium carbonate in dialysis patients over 6 months (from Tzanakis et al. [47], with permission).

phosphate binder in Europe [50]. Another agent in development is iron-magnesium hydroxycarbonate, which can also provide good phosphate control and is generally well tolerated [51]. It has recently been suggested that further large studies are needed to establish the efficacy and safety of magnesium in CKD and, probably, to re-evaluate its appropriate concentration in haemodialysis and continuous ambulatory peritoneal dialysis fluids [52].

\section{Bone, Vascular Calcification, and Patient-Level Outcomes with Current Phosphate Binders}

\section{Sevelamer Hydrochloride and Carbonate}

Five key clinical trials have been conducted to evaluate the progression of coronary calcification in CKD patients: Treat to Goal (TTG) [53], Renagel in New Dialysis (RIND) [54], Calcium Acetate-Renagel Evaluation-2 (CARE-2) [55] and Bone Relationship with Inflammation and Coronary Calcification (BRiC) [26] in dialysis patients and the study by Russo et al. [34] in CKD patients not on dialysis. Three of these studies showed a reduction of calcification progression with sevelamer $[34,53,54]$ and two of them did not $[26,55]$.

Sevelamer has been shown to attenuate vascular calcification progression compared with standard calcium therapy both in CKD stage 3-5 and dialysis patients. Russo et al. [34] showed differences in vascular calcification progression in CKD 3-5 patients randomised to receive dietary phosphate restriction alone, phosphate restriction + calcium carbonate, or phosphate restriction + sevelamer. The highest progression of calcification was reported with dietary restriction, modest progression with calcium carbonate, and reduced progression with sevelamer. In the TTG study, sevelamer markedly reduced vascular calcification progression versus calciumbased therapy in prevalent dialysis patients [53]. Similarly, the RIND study demonstrated important reduction of calcification with sevelamer use in incident dialysis patients [54]. In addition, a large observational study of US dialysis patients also identified potential clinical benefit associated with sevelamer versus calcium in a real-world clinical setting [56].

Two other studies, however, did not show a significant difference in vascular calcification progression between prevalent haemodialysis patients treated with sevelamer and calcium $[26,55]$. In the BRiC study, treatment comparisons may have been confounded by a higher mortality rate in the calcium group compared with the sevelamer group [26]. Thus, patients with more severe calcification may have been eliminated from the analysis. In addition, all patients with low bone turnover on the baseline bone biopsy received lower dialysate calcium, which has been associated with reduced coronary calcification progression in other studies [57], so this difference may have contributed to lower progression of calcification in both groups. In the CARE-2 study, there was similar, but unusually high, progression of calcification in both treatment groups. This analysis may, however, have been confounded by the substantial calcification progression (not seen in other sevelamer trials), which could reflect the high prevalence of cardiovascular risk factors as well as high PTH levels at baseline among the study population [58]. The very high rate of statin therapy used to improve the lipid profile may also have influenced the calcification rates in both groups.

The discrepancy of the results from these different clinical trials deserves further consideration. The key reason for negative results in clinical trials in nephrology is the fact that most of these studies are performed in prevalent patients rather than incident dialysis patients; prevalent patients being a selected group of survivors that may affect the outcome from clinical interventions [59]. The issue of studying the effect of interventions in renal replacement therapy therefore is patient selection and risk factors.

The methodology employed may also have affected the statistical analysis. All these five studies are based in 
a paired analysis, where the patient is his/her own control. The high number of dropouts and/or deaths in some of these studies may influence the final statistical results.

In addition, the rate of progression of vascular calcification may depend on the amount of vascular calcification present at the beginning of the therapeutic intervention. In a study of coronary artery calcification in patients new to haemodialysis, vascular calcification in incident patients with a zero coronary artery calcium score at baseline did not progress at all over an 18-month treatment period with sevelamer or a calcium-containing binder [54].

Development and progression of vascular calcification depend on a complex balance between inducer and inhibitor factors, and a therapeutic intervention against only one factor may not be enough to reverse or stabilize vascular calcification emergence and progression. One possible confounding issue is related to the potential beneficial effect on vascular calcification of moderate acidosis induced by sevelamer hydrochloride. Animal data support the beneficial effect of metabolic acidosis in inhibiting extraskeletal calcification [60].

A limited number of studies have evaluated the effects of sevelamer versus calcium on bone health. Salusky et al. [61] showed sevelamer could reduce bone turnover in patients with high-turnover bone disease but that calcium improved bone mineral in those with altered bone mineralisation. Ferreira et al. [62] suggested sevelamer, but not calcium, resulted in improved bone formation and trabecular architecture in dialysis patients, whereas neither treatment affected bone turnover or mineralisation. The BRiC study showed no differences in bone remodelling between sevelamer or calcium groups [26], although a selection and survival bias as well as the use of lower dialysate calcium in patients with low bone turnover may have contributed to this lack of difference between the treatment groups [63]. It is unclear whether these bone parameters translate into differences in bone strength, but some evidence suggests increases in bone density with sevelamer over calcium in dialysis patients $[63,64]$.

Sevelamer consistently improves lipid profile compared with calcium in dialysis patients $[54,65]$. It can also improve calcification and inflammatory mediators including C-reactive protein [66] and fetuin-A [67]. A recent report has also suggested greater reductions in FGF23 with sevelamer versus calcium in patients with CKD stages 3-5 and dialysis patients [68]. It has been hypothesized that these effects may be associated with beneficial effects beyond those linked with lower phosphorus levels in CKD [69].

Non-Calcium-Containing Phosphate Binders
The effects of sevelamer on the bone and vascular axis, and potentially its pleiotropic effects, may translate into clinical benefits. This hypothesis is supported by data from several large studies that have shown improved clinical outcomes with sevelamer versus calcium. The RIND study showed a lower rate of mortality in new dialysis patients [25]. The Dialysis Clinical Outcomes Revisited (DCOR) study found no differences in the overall study population of prevalent dialysis patients, but showed mortality rates did improve in an elderly subgroup over 65 years and in those with at least 2 years' follow-up [65]. These two studies demonstrated potential differences in clinical outcomes between non-calcium and calcium-based phosphate binders, although Jamal et al. [70] could find no statistically significant difference, in a meta-analysis of cardiovascular mortality and coronary artery calcification, between CKD patients receiving calcium-based compared with non-calcium-based phosphate binders. Conclusions were that there were still potentially important beneficial effects and that further randomized trials were required [70].

In addition, a recent systematic review showed that there was no significant decrease in all-cause mortality, hospitalization, or end-of-treatment serum calciumphosphorus product levels with sevelamer compared with calcium-based agents [27]. There was, however, a significant decrease in end-of-treatment phosphorus and PTH levels with calcium salts compared with sevelamer [27].

\section{Lanthanum Carbonate}

Only recently has a pilot, randomized controlled study been conducted to determine the effect of lanthanum carbonate versus calcium carbonate on vascular calcification in 45 haemodialysis patients [71]. Seventeen lanthanum carbonate patients and 13 calcium carbonate patients completed the study; the results showed that lanthanum carbonate was associated with reduced progression of aortic calcification compared with calcium carbonate over 18 months [71]. D'Haese et al. [72] showed that, in lanthanum-treated patients, there was almost no evolution toward low bone turnover over 1 year, unlike that seen in calcium-treated patients. The number of lanthanum-treated patients versus calcium-treated patients having either adynamic bone, osteomalacia, or hyperparathyroidism decreased overall from 12 (36\%) at baseline to $6(18 \%)$ versus $13(43 \%)$ to $16(53 \%)$, respectively. Malluche et al. [73] similarly showed lanthanum improved bone turnover and volume compared with calcium in patients with renal osteodystrophy.

Nephron Clin Pract 2012;120:c108-c119

c113 
Although no prospective outcomes studies have been designed specifically to assess the effects of lanthanum carbonate, a recent post-hoc survival analysis was undertaken versus standard therapy [74]. This analysis suggested that lanthanum carbonate, like sevelamer, may offer survival benefit in dialysis patients over 65 years of age, but was insufficiently powered to determine differences in patients with $>2$ years' treatment. Given the retrospective nature of this study, further prospective trials are needed to confirm whether there is a consistent trend in patient-level outcomes with lanthanum use.

\section{Magnesium Salts}

It has recently been hypothesized that magnesiumbased P-binders could reduce hyperphosphataemia and improve vascular calcification, based on observational data from studies of magnesium and PTH levels during long-term dialysis, and on magnesium salts in CKD patients [75]. These data found high serum magnesium levels are associated with reduced PTH levels, which may affect bone disease. Several trials also found a link between higher serum magnesium and less vascular calcification, which may have potential positive cardiovascular implications [76, 77].

To date, few prospective studies have assessed the effects of magnesium salts on bone histology, vascular calcification, and CVD morbidity and mortality. Several small studies have tentatively reported bone health and cardiovascular benefits in that magnesium citrate did not change phosphate control but improved carotid intima media thickness compared with calcium acetate over a 2 -month period [77]. In another study, magnesium carbonate combined with calcium carbonate controlled phosphate control without progression of calcification or changes in bone mass over an 18-month period [76]. However, further larger and longer-term clinical studies are needed to establish any beneficial effects of magnesium on bone and vascular health, as well as clinical outcomes [42].

\section{Safety Data, Tolerability, and Concerns around Current Phosphate Binders}

\section{Sevelamer Hydrochloride and Carbonate}

Sevelamer hydrochloride and sevelamer carbonate are associated with gastrointestinal adverse events $[25,78]$. A recent systematic review concluded that there was a significant increase in risk of gastrointestinal adverse events with sevelamer in comparison with calcium salts [27]; however, a study by Delmez et al. [35] showed fewer gastrointestinal events with sevelamer carbonate than with sevelamer hydrochloride, indicating that it may be an option for patients unable to tolerate the latter. Sevelamer hydrochloride releases chloride ions in the intestines that can lead to small increases in serum chloride and small decreases in bicarbonate levels. This may carry a theoretical risk of mild acidosis, which can be corrected easily with dialysis, but means chloride and bicarbonate levels should be monitored. Sevelamer carbonate is not associated with this issue, however, and thus eliminates the need for this consideration [35].

\section{Lanthanum Carbonate}

Lanthanum use is also associated with some gastrointestinal side effects that occur with short- and longterm use [40]. Experimental data have shown that lanthanum accumulates in tissues, such as liver and brain $[79,80]$, and accumulation in bone has also been noted in human studies [81, 82]. Lanthanum use has been shown to substantially increase plasma lanthanum levels in dialysis patients compared with calcium use over 1 year, with plasma levels decreasing significantly over the subsequent 2-year period following discontinuation [82]. In the same group of patients, the bone content of lanthanum increased significantly over 1 year of treatment and remained similarly elevated for 2 years following discontinuation. This finding suggests that lanthanum carbonate bone accumulation is difficult to improve after discontinuation of therapy. Furthermore, bone biopsies of dialysis patients treated with lanthanum carbonate for up to 4.5 years showed increasing levels of lanthanum over time [83]. The impact of this finding on bone health is still unknown, since bone biopsy data following long-term treatment with lanthanum carbonate in a larger number of patients does not yet exist.

Lanthanum was reported to have no effect on decline in cognitive function versus standard phosphate binder therapy in dialysis patients over 2 years; however, a substantially higher dropout and shorter follow-up in the lanthanum group versus standard treatment group may limit the conclusions of this study [84].

Long-term studies of lanthanum have found no major indication of liver, bone, or CNS effects after 1-3 years $[85,86]$. In addition, another study identified no clinically relevant safety issues for up to 6 years in a small select number of dialysis patients who continued from several previous clinical studies $[87,88]$. These limited data are supportive of the long-term safety pro- 
Table 1. Proportion of patients receiving sevelamer or lanthanum reaching KDOQI phosphate target

\begin{tabular}{lllrll}
\hline Drug & Study (first author) & $\begin{array}{l}\text { Haemodialysis/ } \\
\text { pre-dialysis (CKD) }\end{array}$ & $\begin{array}{l}\text { Patients } \\
\mathrm{n}\end{array}$ & Weeks & $\begin{array}{l}\text { Patients reaching KDOQI } \\
\text { phosphate target, \% }\end{array}$ \\
\hline Sevelamer & Delmez, 2007 [35] & haemodialysis & 79 & 8 & 71 \\
& Fishbane, 2010 [31] & haemodialysis & 72 & 24 & 64 (tablets t.i.d.) \\
& Fishbane, 2010 [31] & haemodialysis & 141 & 24 & 54 (powder q.d.) \\
& Ketteler, 2008 [33] & pre-dialysis & 46 & 8 & 70 \\
\hline \multirow{2}{*}{ Lanthanum } & Hutchison, 2005 [92] & haemodialysis & 533 & 5 & 58 \\
& Hutchison, 2008 [37] & haemodialysis & 367 & 12 & 48 \\
& Mehrotra, 2008 [38] & haemodialysis & 513 & 8 & 54 \\
& Sprague, 2009 [39] & pre-dialysis & 80 & 8 & 45 \\
\hline
\end{tabular}

file of lanthanum, but may not include sufficient followup of enough patients to exclude the possibility of clinically important adverse events associated with accumulation. Indeed, past experience with aluminium hydroxide serves as a caution to the use of any binder that will likely accumulate, especially in patients with diminished renal capacity to eliminate. Importantly, the toxic effects of aluminium are now well known, but it took close to a decade of widespread use before these became apparent. There was very limited information on aluminium from preclinical studies, and preclinical toxicological studies were not performed prior to the use of aluminium-based phosphate binders in dialysis patients. The situation would have been different if, as with lanthanum, the toxicity of aluminium had been evaluated first in animals.

\section{Magnesium Salts}

Several studies have suggested that magnesium carbonate use is generally well tolerated. Hypermagnesaemia is not typically a major issue as it can be readily mitigated through dialysis, although since elimination of magnesium is dependent on kidney function, patients may still suffer intermittent increases in magnesium levels between dialysis sessions. There is, however, a lack of clinical data on longer-term effects of chronic magnesium elevation [75]. It has been clearly documented for some time that magnesium accumulates in bone in dialysis patients [89]. This may have toxic effects which may contribute to mineralisation defects and osteomalacia [81]. There is also a real concern that the suppressive effect of magnesium on PTH could lead to low-turnover bone disease [75].

Non-Calcium-Containing Phosphate Binders

\section{Conclusion}

Lowering and maintaining phosphorus levels is accepted as an important therapeutic goal to improve clinical outcomes in CKD patients. Calcium-based phosphate binders have good clinical efficacy and are the most widely used in clinical practice; however, in patients with reduced or absent kidney function, if there is positive calcium balance and bone pathology that impairs buffering this calcium excess, extraosseus calcification may develop or progress $[19,90]$. In daily clinical practice, it is difficult to calculate correct calcium balance and to diagnose bone disease based on biochemical markers, which means we may need to choose a non-calciumbased phosphate binder to treat hyperphosphataemia.

At present, there are three types of non-calcium-based phosphate binders available: sevelamer, lanthanum carbonate, and magnesium salts. These non-calcium-based phosphate binders can each reduce serum phosphorus levels depending on an adequate prescribed dose and on the adherence of the patient to treatment. Sevelamer and lanthanum carbonate can achieve appropriate serum phosphorus targets, such as those set out by KDOQI, to varying degrees (table 1). Some data, albeit limited, exist that show magnesium salts reduce phosphorus levels. It is, however, not possible to clearly distinguish any of these non-calcium-based agents on the basis of clinical efficacy, as little direct head-to-head evidence currently exists.

Long-term safety is, therefore, another important consideration for phosphate binder use in CKD management. Sevelamer is the only non-calcium-containing phosphate binder that does not have potential for systemic accumulation, and presents extra pleiotropic effects

Nephron Clin Pract 2012;120:c108-c119

c115 
that may impact on CVD. In contrast, lanthanum carbonate and magnesium salts are absorbed in the gut and their route of excretion is biliary for lanthanum and urinary for magnesium. Lanthanum is known to accumulate in treatment up to 1 year, but the effects of chronic accumulation have not yet been entirely established. There are also limited data on the effects of long-term magnesium accumulation on bone health or vascular calcification.

Conclusions from a systematic review/meta-analysis of phosphate binders suggested that further investigations are warranted into the differential effect of phosphate binders on cardiovascular mortality/other patientlevel outcome, and the mineral homeostasis pathway [27]. In addition, Tonelli et al. [91] suggested that further studies need to be conducted to determine whether sevelamer or lanthanum improve clinically relevant outcomes in patients with, or at high risk for, vascular calcification, and to evaluate the safety and benefits of add-on treatment with magnesium carbonate.

In conclusion, there is good phosphate-lowering efficacy across calcium-free phosphate binders and, thus, other factors that influence their relative benefit-risk profile become an increasingly important consideration; further research is clearly warranted.

\section{Acknowledgment}

The editorial assistance of Nick Brown, $\mathrm{PhD}$, and Gill Sperrin, CMPP, CBiol, MSB, of Envision Scientific Solutions, was funded by Genzyme.

\section{References}

1 Spasovski GB: Bone health and vascular calcification relationships in chronic kidney disease. Int Urol Nephrol 2007;39:12091216.

-2 Slatopolsky E, Brown A, Dusso A: Role of phosphorus in the pathogenesis of secondary hyperparathyroidism. Am J Kidney Dis 2001;37(suppl 2):S54-S57.

- 3 Prie D, Urena Torres P, Friedlander G: Latest findings in phosphate homeostasis. Kidney Int 2009;75:882-889.

4 Mathew S, Tustison KS, Sugatani T, Chaudhary LR, Rifas L, Hruska KA: The mechanism of phosphorus as a cardiovascular risk factor in CKD. J Am Soc Nephrol 2008;19: 1092-1105.

$\checkmark 5$ Kestenbaum B, Sampson JN, Rudser KD, Patterson DJ, Seliger SL, Young B, Sherrard DJ, Andress DL: Serum phosphate levels and mortality risk among people with chronic kidney disease. J Am Soc Nephrol 2005;16: 520-528.

6 Voormolen N, Noordzij M, Grootendorst DC, Beetz I, Sijpkens YW, van Manen JG, Boeschoten EW, Huisman RM, Krediet RT, Dekker FW: High plasma phosphate as a risk factor for decline in renal function and mortality in pre-dialysis patients. Nephrol Dial Transplant 2007;22:2909-2916.

-7 Isakova T, Gutierrez OM, Chang Y, Shah A, Tamez H, Smith K, Thadhani R, Wolf M: Phosphorus binders and survival on hemodialysis. J Am Soc Nephrol 2009;20:388-396.

8 Kidney Disease: Improving Global Outcomes (KDIGO) CKD-MBD Work Group: KDIGO clinical practice guideline for the diagnosis, evaluation, prevention, and treatment of chronic kidney disease-mineral and bone disorder (CKD-MBD). Kidney Int Suppl 2009;76(suppl 113):S1-S130.
9 Martin KJ, Gonzalez EA: Prevention and control of phosphate retention/hyperphosphatemia in CKD-MBD: what is normal, when to start, and how to treat? Clin J Am Soc Nephrol 2011;6:440-446.

10 Molony DA, Stephens BW: Derangements in phosphate metabolism in chronic kidney diseases/end-stage renal disease: therapeutic considerations. Adv Chronic Kidney Dis 2011;18:120-131.

11 National Kidney Foundation: KDOQI Clinical Practice Guidelines for Bone Metabolism and Disease in Chronic Kidney Disease. Am J Kidney Dis 2003;42(suppl 3):S1-S201.

- 12 Takeda E, Yamamoto H, Nishida Y, Sato T, Sawada N, Taketani Y: Phosphate restriction in diet therapy. Contrib Nephrol. Basel, Karger, 2007, vol 155, pp 113-124.

13 Benini O, D’Alessandro C, Gianfaldoni D, Cupisti A: Extra-phosphate load from food additives in commonly eaten foods: a real and insidious danger for renal patients. J Ren Nutr 2011;21:303-308.

14 Shinaberger CS, Greenland S, Kopple JD, Van Wyck D, Mehrotra R, Kovesdy CP, Kalantar-Zadeh K: Is controlling phosphorus by decreasing dietary protein intake beneficial or harmful in persons with chronic kidney disease? Am J Clin Nutr 2008;88:15111518.

15 Pohlmeier R, Vienken J: Phosphate removal and hemodialysis conditions. Kidney Int Suppl 2001;78:S190-S194.

16 Mudge DW, Johnson DW, Hawley CM, Campbell SB, Isbel NM, van Eps CL, Petrie JJ: Does aluminium continue to have a role as a phosphate binder in contemporary practice? BMC Nephrol 2011;12:20.

17 Slatopolsky E, Weerts C, Norwood K, Giles K, Fryer P, Finch J, Windus D, Delmez J:
Long-term effects of calcium carbonate and $2.5 \mathrm{mEq} /$ liter calcium dialysate on mineral metabolism. Kidney Int 1989;36:897-903.

18 Emmett M, Sirmon MD, Kirkpatrick WG, Nolan CR, Schmitt GW, Cleveland MB: Calcium acetate control of serum phosphorus in hemodialysis patients. Am J Kidney Dis 1991;17:544-550.

19 Bushinsky DA: Contribution of intestine, bone, kidney, and dialysis to extracellular fluid calcium content. Clin J Am Soc Nephrol 2010;5(suppl 1):S12-S22.

20 Renagel tablets (sevelamer hydrochloride) (prescribing information). Cambridge/ Mass, Genzyme Corp, 2007.

21 Renvela (sevelamer carbonate) tablets or for oral suspension (prescribing information). Cambridge/Mass, Genzyme Corp, 2009.

22 Slatopolsky EA, Burke SK, Dillon MA: Renagel, a nonabsorbed calcium- and aluminumfree phosphate binder, lowers serum phosphorus and parathyroid hormone. The RenaGel Study Group. Kidney Int 1999;55: 299-307.

23 Chertow GM, Dillon M, Burke SK, Steg M, Bleyer AJ, Garrett BN, Domoto DT, Wilkes BM, Wombolt DG, Slatopolsky EA: A randomized trial of sevelamer hydrochloride (renagel) with and without supplemental calcium. Strategies for the control of hyperphosphatemia and hyperparathyroidism in hemodialysis patients. Clin Nephrol 1999;51: $18-26$.

24 Braun J, Asmus HG, Holzer H, Brunkhorst R, Krause R, Schulz W, Neumayer HH, Raggi P, Bommer J: Long-term comparison of a calcium-free phosphate binder and calcium carbonate-phosphorus metabolism and cardiovascular calcification. Clin Nephrol 2004;62:104-115. 
-25 Block GA, Raggi P, Bellasi A, Kooienga L, Spiegel DM: Mortality effect of coronary calcification and phosphate binder choice in incident hemodialysis patients. Kidney Int 2007;71:438-41.

-26 Barreto DV, Barreto Fde C, de Carvalho AB, Cuppari L, Draibe SA, Dalboni MA, Moyses RM, Neves KR, Jorgetti V, Miname M, Santos RD, Canziani ME: Phosphate binder impact on bone remodeling and coronary calcification - results from the BRiC study. Nephron Clin Pract 2008;110:c273-c283.

$\checkmark 27$ Navaneethan SD, Palmer SC, Craig JC, Elder GJ, Strippoli GF: Benefits and harms of phosphate binders in CKD: a systematic review of randomized controlled trials. Am J Kidney Dis 2009;54:619-637.

-28 De Francisco AL, Leidig M, Covic AC, Ketteler M, Benedyk-Lorens E, Mircescu GM, Scholz C, Ponce P, Passlick-Deetjen J: Evaluation of calcium acetate/magnesium carbonate as a phosphate binder compared with sevelamer hydrochloride in haemodialysis patients: a controlled randomized study (CALMAG study) assessing efficacy and tolerability. Nephrol Dial Transplant 2010;25:3707-3717.

29 Spasovski G, Vanholder R: Is combined calcium/magnesium phosphate binder really noninferior to sevelamer hydrochloride? Nephrol Dial Transplant 2011;26:1442-1444.

30 Fan S, Ross C, Mitra S, Kalra P, Heaton J, Hunter J, Plone M, Pritchard N: A randomized, crossover design study of sevelamer carbonate powder and sevelamer hydrochloride tablets in chronic kidney disease patients on haemodialysis. Nephrol Dial Transplant 2009;24:3794-3799.

- 31 Fishbane S, Delmez J, Suki WN, Hariachar SK, Heaton J, Chasan-Taber S, Plone MA, Moe S: A randomized, parallel, open-label study to compare once-daily sevelamer carbonate powder dosing with thrice-daily sevelamer hydrochloride tablet dosing in CKD patients on hemodialysis. Am J Kidney Dis 2010;55:307-15.

- 32 Evenepoel P, Selgas R, Caputo F, Foggensteiner L, Heaf JG, Ortiz A, Kelly A, ChasanTaber S, Duggal A, Fan S: Efficacy and safety of sevelamer hydrochloride and calcium acetate in patients on peritoneal dialysis. Nephrol Dial Transplant 2009;24:278-285.

-33 Ketteler M, Rix M, Fan S, Pritchard N, Oestergaard O, Chasan-Taber S, Heaton J, Duggal A, Kalra PA: Efficacy and tolerability of sevelamer carbonate in hyperphosphatemic patients who have chronic kidney disease and are not on dialysis. Clin J Am Soc Nephrol 2008;3:1125-1130.

34 Russo D, Miranda I, Ruocco C, Battaglia Y, Buonanno E, Manzi S, Russo L, Scafarto A, Andreucci VE: The progression of coronary artery calcification in predialysis patients on calcium carbonate or sevelamer. Kidney Int 2007;72:1255-1261.
5 Delmez J, Block G, Robertson J, ChasanTaber S, Blair A, Dillon M, Bleyer AJ: A randomized, double-blind, crossover design study of sevelamer hydrochloride and sevelamer carbonate in patients on hemodialysis. Clin Nephrol 2007;68:386-391.

36 Al-Baaj F, Speake M, Hutchison AJ: Control of serum phosphate by oral lanthanum carbonate in patients undergoing haemodialysis and continuous ambulatory peritoneal dialysis in a short-term, placebo-controlled study. Nephrol Dial Transplant 2005;20: 775-782.

37 Hutchison AJ, Laville M: Switching to lanthanum carbonate monotherapy provides effective phosphate control with a low tablet burden. Nephrol Dial Transplant 2008;23: 3677-3684.

38 Mehrotra R, Martin KJ, Fishbane S, Sprague SM, Zeig S, Anger M: Higher strength lanthanum carbonate provides serum phosphorus control with a low tablet burden and is preferred by patients and physicians: a multicenter study. Clin J Am Soc Nephrol 2008; 3:1437-1445

39 Sprague SM, Abboud H, Qiu P, Dauphin M, Zhang P, Finn W: Lanthanum carbonate reduces phosphorus burden in patients with CKD stages 3 and 4: a randomized trial. Clin J Am Soc Nephrol 2009;4:178-185.

40 Hutchison AJ, Maes B, Vanwalleghem J, Asmus G, Mohamed E, Schmieder R, Backs W, Jamar R, Vosskuhler A: Long-term efficacy and tolerability of lanthanum carbonate: results from a 3-year study. Nephron Clin Pract 2006;102:c61-c71.

-41 Sprague SM, Ross EA, Nath SD, Zhang P, Pratt RD, Krause R: Lanthanum carbonate vs. sevelamer hydrochloride for the reduction of serum phosphorus in hemodialysis patients: a crossover study. Clin Nephrol 2009;72:252-258.

42 Spiegel DM: Magnesium in chronic kidney disease: unanswered questions. Blood Purif 2011;31:172-176.

-43 Oe PL, Lips P, van der Meulen J, de Vries PM, van Bronswijk H, Donker AJ: Long-term use of magnesium hydroxide as a phosphate binder in patients on hemodialysis. Clin Nephrol 1987;28:180-185.

44 Moriniere P, Vinatier I, Westeel PF, Cohemsolal M, Belbrik S, Abdulmassih Z, Hocine C, Marie A, Leflon P, Roche D, et al: Magnesium hydroxide as a complementary aluminium-free phosphate binder to moderate doses of oral calcium in uraemic patients on chronic haemodialysis: lack of deleterious effect on bone mineralisation. Nephrol Dial Transplant 1988;3:651-656.

45 Parsons V, Baldwin D, Moniz C, Marsden J, Ball E, Rifkin I: Successful control of hyperparathyroidism in patients on continuous ambulatory peritoneal dialysis using magnesium carbonate and calcium carbonate as phosphate binders. Nephron 1993;63:379383.
46 Delmez JA, Kelber J, Norword KY, Giles KS, Slatopolsky E: Magnesium carbonate as a phosphorus binder: a prospective, controlled, crossover study. Kidney Int 1996;49: 163-167.

47 Tzanakis IP, Papadaki AN, Wei M, Kagia S, Spadidakis VV, Kallivretakis NE, Oreopoulos DG: Magnesium carbonate for phosphate control in patients on hemodialysis. A randomized controlled trial. Int Urol Nephrol 2008;40:193-201.

48 Deuber HJ: Long-term efficacy and safety of an oral phosphate binder containing both calcium acetate and magnesium carbonate in hemodialysis patients. Nieren Hochdruck 2004;33:403-408.

-49 Spiegel DM, Farmer B, Smits G, Chonchol M Magnesium carbonate is an effective phosphate binder for chronic hemodialysis patients: a pilot study. J Ren Nutr 2007;17:416422

50 Osvaren (calcium acetate $435 \mathrm{mg} / \mathrm{magne}$ sium carbonate $235 \mathrm{mg}$ ) film-coated tablets. Summary of product characteristics. Fresenius Medical Care Nephrologica Bad Homburg, Germany.

51 McIntyre CW, Pai P, Warwick G, Wilkie M, Toft AJ, Hutchison AJ: Iron-magnesium hydroxycarbonate (Fermagate): a novel noncalcium-containing phosphate binder for the treatment of hyperphosphatemia in chronic hemodialysis patients. Clin J Am Soc Nephrol 2009;4:401-409.

-52 Tzanakis IP, Oreopoulos DG: Beneficial effects of magnesium in chronic renal failure: a foe no longer. Int Urol Nephrol 2009;41: 363-371.

53 Chertow GM, Burke SK, Raggi P: Sevelamer attenuates the progression of coronary and aortic calcification in hemodialysis patients. Kidney Int 2002;62:245-252.

-54 Block GA, Spiegel DM, Ehrlich J, Mehta R, Lindbergh J, Dreisbach A, Raggi P: Effects of sevelamer and calcium on coronary artery calcification in patients new to hemodialysis. Kidney Int 2005;68:1815-1824

55 Qunibi W, Moustafa M, Muenz LR, He DY, Kessler PD, Diaz-Buxo JA, Budoff M: A 1-year randomized trial of calcium acetate versus sevelamer on progression of coronary artery calcification in hemodialysis patients with comparable lipid control: the Calcium Acetate Renagel Evaluation-2 (CARE-2) study. Am J Kidney Dis 2008;51:952-965.

56 Borzecki AM, Lee A, Wang SW, Brenner L, Kazis LE: Survival in end stage renal disease: calcium carbonate vs. sevelamer. J Clin Pharm Ther 2007;32:617-624

57 Igarashi P, Aronson PS: Late-breaking clinical trials at renal week. Clin J Am Soc Nephrol 2008;3:RB01-RB04.

58 Floege J: Calcium-containing phosphate binders in dialysis patients with cardiovascular calcifications: should we CARE-2 avoid them? Nephrol Dial Transplant 2008; 23:3050-3052. 
-59 Jager KJ, Stel VS, Zoccali C, Wanner C, Dekker FW: The issue of studying the effect of interventions in renal replacement therapy - to what extent may we be deceived by selection and competing risk? Nephrol Dial Transplant 2010;25:3836-3839.

60 Mendoza FJ, Lopez I, Montes de Oca A, Perez J, Rodriguez M, Aguilera-Tejero E: Metabolic acidosis inhibits soft tissue calcification in uremic rats. Kidney Int 2008; 73:407-414.

61 Salusky IB, Goodman WG, Sahney S, Gales B, Perilloux A, Wang HJ, Elashoff RM, Juppner H: Sevelamer controls parathyroid hormone-induced bone disease as efficiently as calcium carbonate without increasing serum calcium levels during therapy with active vitamin D sterols. J Am Soc Nephrol 2005;16:2501-2508.

-62 Ferreira A, Frazao JM, Monier-Faugere MC, Gil C, Galvao J, Oliveira C, Baldaia J, Rodrigues I, Santos C, Ribeiro S, Hoenger RM, Duggal A, et al: Effects of sevelamer hydrochloride and calcium carbonate on renal osteodystrophy in hemodialysis patients. J Am Soc Nephrol 2008;19:405-412.

-63 Raggi P, James G, Burke SK, Bommer J, Chasan-Taber S, Holzer H, Braun J, Chertow GM: Decrease in thoracic vertebral bone attenuation with calcium-based phosphate binders in hemodialysis. J Bone Miner Res 2005;20:764-772.

-64 Asmus HG, Braun J, Krause R, Brunkhorst R, Holzer H, Schulz W, Neumayer HH, Raggi P, Bommer J: Two-year comparison of sevelamer and calcium carbonate effects on cardiovascular calcification and bone density. Nephrol Dial Transplant 2005;20:16531661.

-65 Suki WN, Zabaneh R, Cangiano JL, Reed J, Fischer D, Garrett L, Ling BN, Chasan-Taber S, Dillon MA, Blair AT, Burke SK: Effects of sevelamer and calcium-based phosphate binders on mortality in hemodialysis patients. Kidney Int 2007;72:1130-1137.

- 66 Shantouf R, Budoff MJ, Ahmadi N, Tiano J, Flores F, Kalantar-Zadeh K: Effects of sevelamer and calcium-based phosphate binders on lipid and inflammatory markers in hemodialysis patients. Am J Nephrol 2008;28:275-279.

- 67 Caglar K, Yilmaz MI, Saglam M, Cakir E, Acikel C, Eyileten T, Yenicesu M, Oguz Y, Vural A, Carrero JJ, Axelsson J, Lindholm B, et al: Short-term treatment with sevelamer increases serum fetuin-A concentration and improves endothelial dysfunction in chronic kidney disease stage 4 patients. Clin J Am Soc Nephrol 2008;3:61-68.

68 Oliveira RB, Cancela AL, Graciolli FG, Dos Reis LM, Draibe SA, Cuppari L, Carvalho $A B$, Jorgetti V, Canziani ME, Moysés RM: Early control of PTH and FGF-23 in normophosphatemic CKD patients: a new target in CKD-MBD therapy? Clin J Am Soc Nephrol 2010;5:286-291.
69 Striker GE: Beyond phosphate binding: the effect of binder therapy on novel biomarkers may have clinical implications for the management of chronic kidney disease patients. Kidney Int 2009;76(suppl 114):S1-S2.

-70 Jamal SA, Fitchett D, Lok CE, Mendelssohn DC, Tsuyuki RT: The effects of calciumbased versus non-calcium-based phosphate binders on mortality among patients with chronic kidney disease: a meta-analysis. Nephrol Dial Transplant 2009;24:31683174.

71 Toussaint ND, Lau KK, Polkinghorne KR, Kerr PG: Attenuation of aortic calcification with lanthanum carbonate versus calciumbased phosphate binders in haemodialysis: a pilot randomized controlled trial. Nephrology (Carlton) 2011;16:290-298.

72 D'Haese PC, Spasovski GB, Sikole A, Hutchison A, Freemont TJ, Sulkova S, Swanepoel C, Pejanovic S, Djukanovic L, Balducci A, Coen G, Sulowicz W, et al: A multicenter study on the effects of lanthanum carbonate (Fosrenol) and calcium carbonate on renal bone disease in dialysis patients. Kidney Int Suppl 2003;S73-S78.

73 Malluche HH, Siami GA, Swanepoel C, Wang GH, Mawad H, Confer S, Smith M, Pratt RD, Monier-Faugere MC: Improvements in renal osteodystrophy in patients treated with lanthanum carbonate for two years. Clin Nephrol 2008;70:284-295.

74 Wilson R, Zhang P, Smyth M, Pratt R: Assessment of survival in a 2-year comparative study of lanthanum carbonate versus standard therapy. Curr Med Res Opin 2009;25: 3021-3028.

-75 Navarro-Gonzalez JF, Mora-Fernandez C, Garcia-Perez J: Clinical implications of disordered magnesium homeostasis in chronic renal failure and dialysis. Semin Dial 2009; 22:37-44.

76 Spiegel DM, Farmer B: Long-term effects of magnesium carbonate on coronary artery calcification and bone mineral density in hemodialysis patients: a pilot study. Hemodial Int 2009;13:453-459.

77 Turgut F, Kanbay M, Metin MR, Uz E, Akcay A, Covic A: Magnesium supplementation helps to improve carotid intima media thickness in patients on hemodialysis. Int Urol Nephrol 2008;40:1075-1082.

78 Suki WN: Effects of sevelamer and calciumbased phosphate binders on mortality in hemodialysis patients: results of a randomized clinical trial. J Ren Nutr 2008;18:91-98.

79 Slatopolsky E, Liapis H, Finch J: Progressive accumulation of lanthanum in the liver of normal and uremic rats. Kidney Int 2005;68: 2809-2813.

80 Nikolov IG, Joki N, Vicca S, Patey N, Auchere D, Flinois JP, Beaune P, Drueke T, Lacour B. Effects of long-term lanthanum carbonate administration on tissue La content and liver function in rats with chronic renal failure. ASN Renal Week, San Francisco 2007.
81 Gonella M, Ballanti P, Della Rocca C, Calabrese G, Pratesi G, Vagelli G, Mazzotta A, Bonucci E: Improved bone morphology by normalizing serum magnesium in chronically hemodialyzed patients. Miner Electrolyte Metab 1988;14:240-245.

82 Spasovski GB, Sikole A, Gelev S, Masin-Spasovska J, Freemont T, Webster I, Gill M, Jones C, De Broe ME, D'Haese PC: Evolution of bone and plasma concentration of lanthanum in dialysis patients before, during 1 year of treatment with lanthanum carbonate and after 2 years of follow-up. Nephrol Dial Transplant 2006;21:2217-2224.

83 Fosrenol tablets (lanthanum carbonate) (prescribing information). Wayne/Pa, Shire US Inc, Oct 2004.

84 Altmann P, Barnett ME, Finn WF: Cognitive function in stage 5 chronic kidney disease patients on hemodialysis: no adverse effects of lanthanum carbonate compared with standard phosphate-binder therapy. Kidney Int 2007;71:252-259.

85 Finn WF, Joy MS: A long-term, open-label extension study on the safety of treatment with lanthanum carbonate, a new phosphate binder, in patients receiving hemodialysis. Curr Med Res Opin 2005;21:657-664.

86 Finn WF: Lanthanum carbonate versus standard therapy for the treatment of hyperphosphatemia: safety and efficacy in chronic maintenance hemodialysis patients. Clin Nephrol 2006;65:191-202.

87 Hutchison AJ, Barnett ME, Krause R, Kwan JT, Siami GA: Long-term efficacy and safety profile of lanthanum carbonate: results for up to 6 years of treatment. Nephron Clin Pract 2008; 110:c15-c23.

88 Hutchison AJ, Barnett ME, Krause R, Siami GA: Lanthanum carbonate treatment, for up to 6 years, is not associated with adverse effects on the liver in patients with chronic kidney disease stage 5 receiving hemodialysis. Clin Nephrol 2009;71:286-295.

89 Alfrey AC, Miller NL: Bone magnesium pools in uremia. J Clin Invest 1973;52:30193027.

90 Braun J: Extraosseous calcification in patients with chronic renal failure - no escape? Nephrol Dial Transplant 2005;20:20542059.

91 Tonelli M, Pannu N, Manns B: Oral phosphate binders in patients with kidney failure. N Engl J Med 2010;362:1312-1324.

$\checkmark 92$ Hutchison AJ, Maes B, Vanwalleghem J, Asmus G, Mohamed E, Schmieder R, Backs W, Jamar R, Vosskuhler A: Efficacy, tolerability, and safety of lanthanum carbonate in hyperphosphatemia: a 6-month, randomized, comparative trial versus calcium carbonate. Nephron Clin Pract 2005;100:c8-c19. 


\section{Editorial Comment}

Meguid El Nahas, Sheffield

The review by Frazão et al. examines the potential of non-calcium-containing phosphate binders in patients with CKD. They review the evidence based on a number of clinical trials. They conclude that sevelamer and lanthanum carbonate are effective at reducing serum phosphorus levels to those recommended by international guidelines. They also suggest from a small number of studies that sevelamer (Renagel) may have therapeutic advantages in terms of reducing vascular calcifications. This was suggested in the RIND (Renagel In New Dialysis) and TTG (Treat To Goal) studies but not by others such as BRiC and CARE2. Such analysis is of considerable interest and highlights a number of issues: First, the jury is out on the superiority of Renagel over calciumcontaining phosphate binders in terms of vascular calcification. Second, the use of vascular calcifications as surrogate endpoint may be subject to analytical confounders and variability and does not negate the need for hard endpoints such as major cardiovascular events (MACE) or more importantly, mortality. Of interest, in that respect, in the DCOR study, in >2,100 chronic haemodialysis pa- tients, there was no difference in all-cause mortality between sevelamer and calcium-based phosphate binder therapy over a 3-year observation time. Third, as often in nephrology, smaller clinical trials and observational studies tend to show promising effects of interventions that are all too often disappointed by larger studies. In that respect, the recently published INDEPENDENT Study suggested improved survival in CKD3-4 on sevelamer compared to calcium-containing binders, but this pilot study has a number of shortcomings including being underpowered with an inadequate sample size to estimate the difference in mortality, a large dropout rate and absence of intention-to-treat analysis. Fourth, a cost analysis is needed to support the cost:benefit of non-calcium-containing binders, including sevelamer. As so often in nephrology, tempered enthusiasm is warranted for newer agents compared to older ones, but enthusiasm should not replace critical analysis of available evidence as well as the requirement for hard and meaningful clinical endpoints. These remain lacking to favour newer phosphate binders. 